\title{
Amelanotic Cutaneous Melanoma
}

National Cancer Institute

\section{Source}

National Cancer Institute. Amelanotic Cutaneous Melanoma. NCI Thesaurus. Code C4633.

A rare cutaneous melanoma where most of the melanoma tumor cells are devoid of melanin pigment. Amelanotic melanomas are more likely to present at a more advanced stage of disease, compared with pigmented melanomas. 